\section{An Improvised Drill Press} By W. D. Graves

$F^{\mathrm{OR}}$ an occasional light job a large cabinet maker's T clamp and a ratchet brace may be made to serve as a very efficient drill press. A short stout wood screw or flat-headed rivet, with the point filed to a smooth conical point, serves as an end bearing for the brace spindle, while the piece to be drilled is placed agains the end of the clamp screw; all as shown in the accom l:anying photograpll.

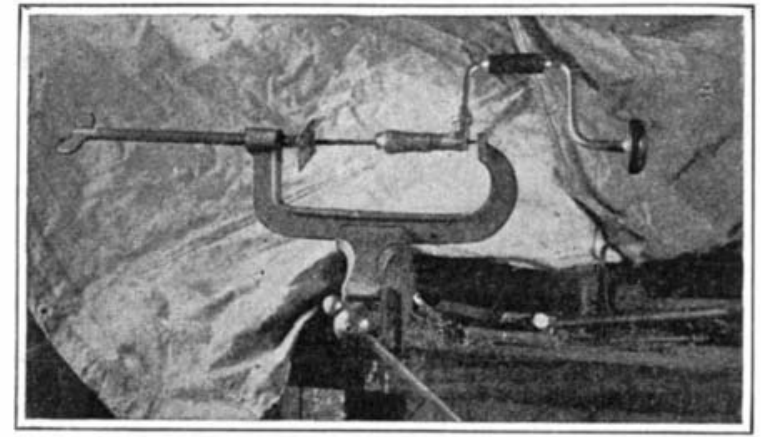

Emergency drill press for light work.

The arrangement is somewhat awkward for one to operate alone, but if he has a helper to turn the brace while he steadies and feeds the work, it is very effective indeed.

\section{Chipping or Dissolving Scale from Cylinders} By George Rice

$T_{\text {HE accompanying drawings show how scale is apt }}$ $\boldsymbol{T}$ to collect in automobile cylinders and accessory parts and also the tools that may be used to remove it While some owners and repairers of automobiles take special steps for the prevention and elimination of scaly matter from the cylinders, others are very care less concerning this bothersome problem, and as a re less concerning this bothersome problem, and as a re-
sult they are apt to have overheated cylinders due to sult they are apt to have overheated cylinders due to the presence of the foreign matter. Of course, scaly accumulations are caused by the use of imperfect water. If hard water is all that is available, water softening and purifying compositions must be employed for dissolving the scale. There are patented mixtures for this purpose. Washing soda is used by some motorists with a certain desree of success.

The accumulated matter about the parts $A$ and $B$ in Fig. 1 was of course sufficient in bulliness to interfere with the passages. In order to remove thi foreign substance the cover was taken off and chipping tools employed for cutting off the bulk of the matter, after which soda solutions were admitted into the cylinder to eat into and woften the remilniug substance. In another case one of the bolt heads inside the cylin and the bo had to be brolien out for removal, as the nut was too
firmly fixed by the foreign substance to permit of turning off on the thread. In another instance the scale had gathered for a long time on the surface of a pipe joint as at $D$, Fig. 3 . In one plice, at $l ;$, a hole was created as a result of the foreign matter gradually eating into the metal shell of the elbow. Finally

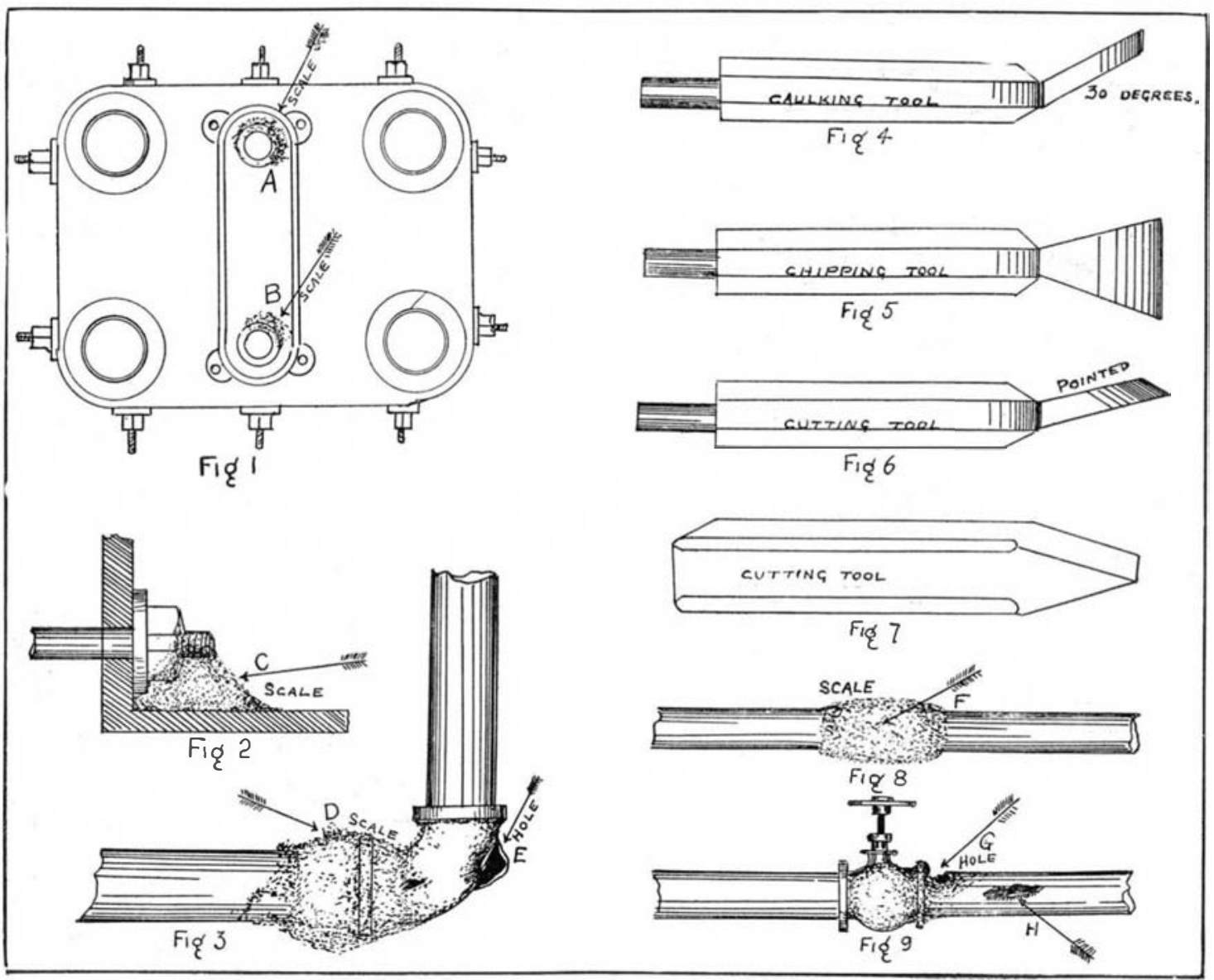

Scale accumulation and tools for removing it. the shell was extremely thin and lacked sufficient power to resist the pressure from within, the metal expanded and broke, making the fracture as shown

In the next four illustrations are shown some patterns of calking and chipping tools of a home-made style. You can buy your chipping tools of this kind in readiness for use in any hardware store or automobile dealing establishment. But often specially forged tools are wanted. You can get the tool steel blanks and have the chisels forged as wanted ind to the pattern required.

Fig. 4 is a calling tool with a 30 -degree nose, and from this slant you can get any degree for the bevel as may be desired for the special service to which you intend to put the chisel. A common form of effective chipping chisel for removing scale from cylinders and pipe surfaces is shown in Fig. 5. A handy cutting tool for chipping into the scaly matter in crevices is shown in Fig. 6. The form in Fig. 7 is useful for the average cutting service on scale formations.

Fig. 8 shows a gathering of scale on a pipe and Fig. 9 all accumulition about one of the check valves. The holes $g$ and $l$ are the result of the foreign matter slow ly but surely weakening the metal by eating into the fiber and destroying it. The thinned surfacing cracks at slight pressure and a hole results. The lest way is to examine the parts of the mechanism liable to be coated with scale from the water and take steps to pre-

\section{Altering a Stethoscope to Locate Motor Knocks}

By William R. Inghram, M.D.

G VERY physician has a stethoscope. Nearly every

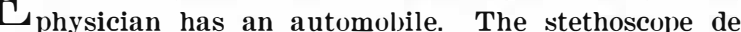
tects an almormal heart sound, and with a slight varia-

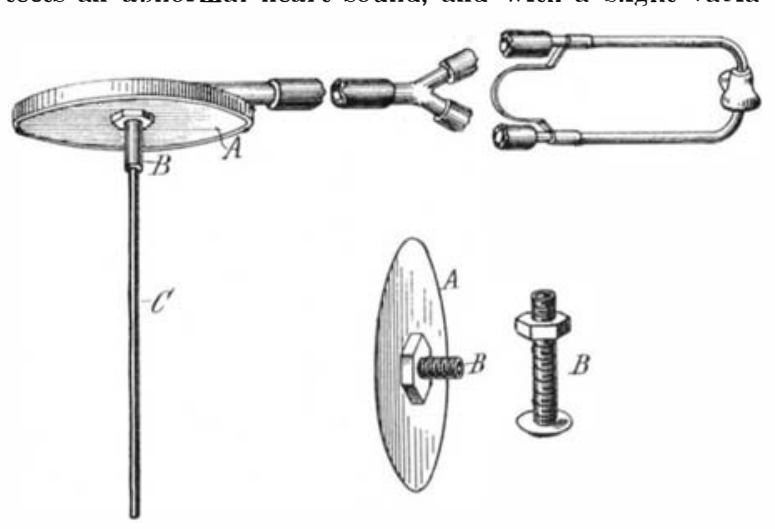

Details of the altered stethoscope.

tion this same instrument detects an abnormal motor sound just as surely.

This is how the writer did it. A new diaphragm is made from a thin piece of hard rubber (an old slide from a photographic plate holder in this case). A brass dry battery bolt cut off to about $3 / 8$-inch and with a hole drilled in the end is placed in the center of the disk and the nut is tightened up.

In the accompanying drawing $A$ is the diaphragm, $B$ the battery bolt and $C$ a heavy wire threaded or other- rass cleaning rod for a 0.22 rifie is just the thing. The device is now ready for use. Place the tubes in the eirs and tap the rod lightly with the finger nail; if a spring brass wire is used, it will sound like the ringing of church bells. The ticling of a watch placed on the floor is plainly heard through the wire. A very slishlit knock in the motor, scarcely heard with the unaided ear, sounds like a heavy hammer blow, througl

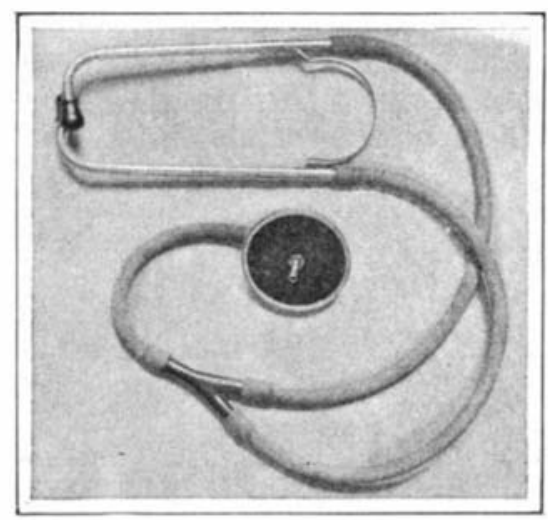

Stethoscope altered to locate motor knocks.

this instrument. A valve gear knock is easily traced to its source by trying one valve after the other. Simply place the end of the wire against the valve lifter housing.

Sitting in the moving car with a long wire in the stethoscope projecting through a crack or hole in the floor, and resting on the differential housing, or transmission, universal joint housing, or wherever suspicions indicate, a knock, squeals or grating is easily traced.

\section{Convenient Wood Steaming} By O. Ruehmer

THE following device for steaming planking on the hulls of small boats will be found very efficient. A box is constructed of light wood or metal of the A box is constructed of light wood or metal of the 12 inches long and of a breadth not greater than the narrowest part of the plank to be bent. The depth is about 4 inches and at the center of the bottom a short piece of iron pipe is secured, to one end of which a hose is attached. A pair of handles can be placed on each side of the pipe to facilitate handling. The edges of the open end should be covered with cloth loosely nailed, or if preferred, weather strips can be nailed on the sides so as to form a tight joint when the whole is pressed up against the board. The board to be bent being in place as shown in Fig. 3, a sling is placed over the end and a stick inserted in the sling to form a tourniquet with which the end of the board may be pulled. Now by applying the steaming box as shown and attaching it by means of a hose to a boiler or kettle the plank is easily bent and the tourniquet tightened. There should be no hurry in moving the box as every part of the plank should be steamed in order to obtain a true curve. A pulley fixed on a firm support can be used instead of the sling. As the planking on the sides of a boat tapers from the center to each end, the box, as stated, should not be wider than the narrowest end. In order, therefore, to get good results when worlsing on the wider part it will be necessary to keep moving the steaming box up and down.
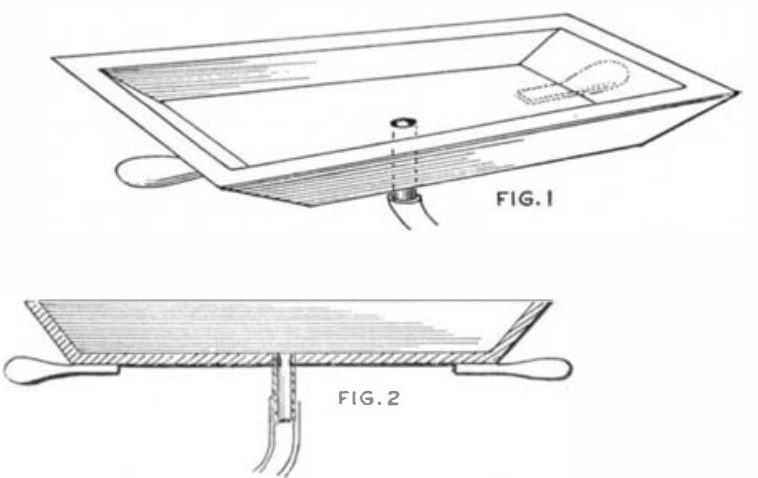

Steam box for boat building.

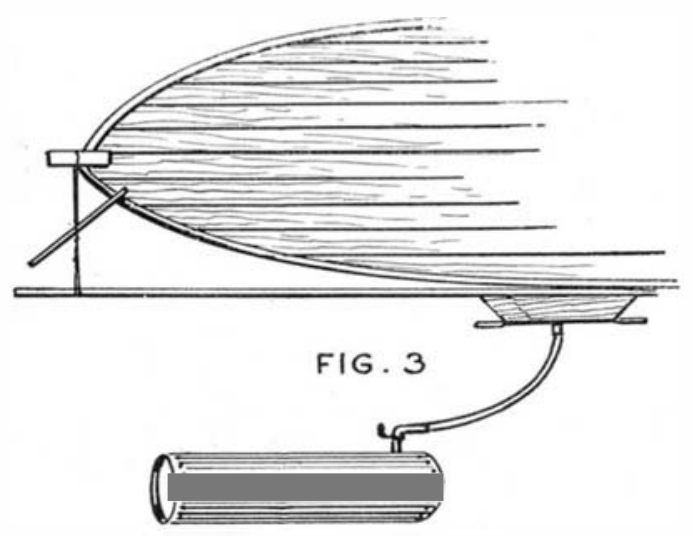

Method of using the steam box. 